\title{
THE MOST SUITABLE CLEARANCE IN MCF (MAGNETIC COMPOUND FLUID) POLISHING
}

\author{
Yaoyang Zheng ${ }^{1 *}$ \\ *IDepartment of Mechanical Engineering Fukushima National College of Technology, 30 Nagao, Kamiarakawa, Taira, \\ Iwaki, Fukushima970-8034, Japan E-mail address: tei@fukushima-nct.ac.jp \\ *Corresponding Author: - \\ E-mail address: tei@fukushima-nct.ac.jp
}

\begin{abstract}
: -
Prof. Shimada has demonstrated experimentally that the polishing effect using our developed intelligent fluid, magnetic compound fluid $(M C F)$, is greater than that using previously developed intelligent fluids, i.e., magnetic fluid $(M F)$ and magneto-rheological fluid (MRF). Shimada succeeded in float polishing with a large clearance utilizing a newly developed magnetic responsive fluid, MCF, which was improved by the addition of a-cellulose, thereby achieving a clearance as great as $8 \mathrm{~mm}$. He also clarified the mechanism of the new polishing technique. A comparison of the MCF polishing effect with those of techniques using the ordinary magnetic responsive fluids, MF and MRF, showed the polishing effect of MCF to be greater than those of MF and MRF. The MCF polishing technique is applicable to many types of polishing, widening the variety of the uses of magnetic float polishing (MFP). However, while clearance to8mm is possible, this may not be the most suitable value. In this study, we clarified the most suitable value for MCF abrasion experimentally.
\end{abstract}

Keywords: - MCF (Magnetic Compound Fluid), polishing, most suitable clearance, polished material

\section{(c) (\$) (i)}




\section{INTRODUCTION}

In order to further develop nano- or micro-technology, nano- or micro-polishing techniques are needed to polish or grind the material surfaces of nano- or micro-devices on a nm-order. In response to this need, Shimada has demonstrated experimentally that the polishing effect using our developed intelligent fluid, magnetic compound fluid (MCF), is greater than that using previously developed intelligent fluids, i.e., MF and MRF [13]. The apparent viscosity of MF under a magnetic field is smaller than that of MRF [4], but the stability of the particles distribution in an MF solvent is greater than that of MRF [4]. Thus, MCF was created by compounding the nm-size magnetite of MF and $\square$ m-size iron particles in a single solvent, essentially producing a mixture of MF and MRF [4]. This new fluid was applied to float polishing [5, $6]$, resulting in a clearance range between the polishing tool and the polished material surface of at most $0.1 \mathrm{~mm}[6,7]$.

However, this clearance range should be larger than that of lapping polishing because float polishing provides two advantages over contact polishing. The first regards float polishing's avoidance of the degeneration or plastic deformation of a polished surface due to contact between the abrasive and magnetic particles on the material's surface [8]. The second advantage lies in float polishing's ability to polish a surface of any shape.

On the other hand, many studies have focused on float polishing that utilized an ordinal magnetic material or magnetic responsive fluid. For example, studies have examined magnetic float polishing (MFP) using magnetic material [9, 10] and float polishing using MF [11, 12] and MRF [13-15]. MFP is expected to be applied in the precision finishing field because of the possibility of controlling the polishing effect by a magnetic field.

Therefore, we have investigated float polishing with a large clearance, utilizing a newly developed magnetic responsive fluid, MCF, which was improved by the addition of $\alpha$-cellulose [16]. By adding $\alpha$-cellulose to MCF, float polishing becomes suitable for large-clearance polishing. With this improvement of MCF, the clearance could be as large as $8 \mathrm{~mm}$. By using this to bath in which a polished specimen is immersed, the polishing effect and the clearance can become even larger. MCF float polishing allows any kind of material to be polished to a smaller Ra, and has a greater polishing effect than do either MF or MRF. The polishing effect of MCF depends on the abrasive particles and on the shear stress along the rotational direction of the polishing tool and MCF. The mechanism of this new MCF polishing technique has been also investigated. Prof. Shimada has succeeded in extracting magnetic clusters from MCF [16]. By using this proposed magnetic clusters' extraction technique, the effect of the abrasive particles within the magnetic clusters was clarified to be larger than that of those outside the magnetic clusters.

To improve abrasion efficiency, however, it is important to determine the most suitable value for the clearance between the polished surface and the polishing tool.

\section{MFC Polishing Device and Tool}

As shown in Fig. 1, we used drill press as experimental apparatus for MCF float polishing. It had a clearance $\delta$ of $1-8 \mathrm{~mm}$ between the polished surface and the polishing tool. MCF using a kerosene-based MF (HC-50, Taiho Industry Co., Ltd., Japan) with $\mathrm{Fe}_{3} \mathrm{O}_{4}$ magnetite particles coated by oleic acid having diameters of $10 \mathrm{~nm}$ and containing abrasive particles of $\mathrm{Al}_{2} \mathrm{O}_{3}$, the carbonyl iron HQ with a mean diameter of 1.2-1.6 $\mu$ m-size (BASF Co., Ltd.,) and a $\alpha$-cellulose that is fibrin and elastic and has the role of being a polishing pad material.

In MCF polishing, the results are significantly related to the experimental conditions. It is necessary to consider about eight polishing conditions for each experiment.

[1] Composition of the abrasion liquid (weight ratio)

[2] Clearance (gap) between the polished body surface and the polishing tool

[3] Rotary speed of the polishing tool

[4] Duration of polishing

[5] Surface magnetic induction of the neodymium magnet: a rectangular neodymium magnet is fixed to the head, and the surface magnetic induction of the neodymium magnet is about 2,600 gausses.

[6] Material of the polishing body

[7] Motion form of the polishing tool

[8] Shape of the polishing tool

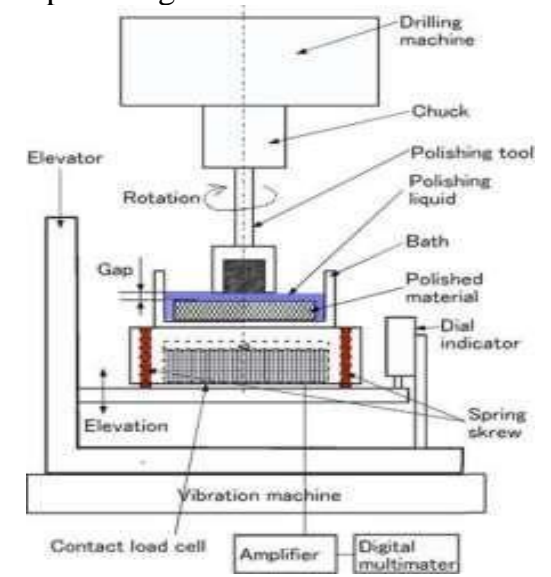

Fig. 1 Schematic diagram of MCF float polishing machine.

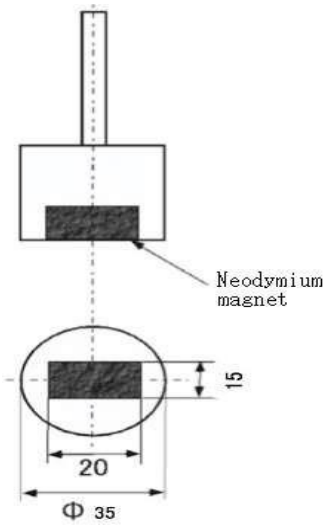

Fig. 2 Polishing Tool 


\section{Experimental Conditions And Method}

Tables 1 and 2 list the compoments of two different polishing liquids. We used these liquids for experiments under various polishing conditions, presented in Tables 3-6. Figs. 3-6 show the polishing results corresponding to the conditions listed in the tables. When clearance (gap) of the polishing tool and polished surface became $4 \mathrm{~mm}$, Fig3 Fig6 indicated difference between roughness after polishing and initial roughness was the biggest.

TABLE. 1 POLISHING LIQUID 1 (PL1)

\begin{tabular}{|c|c|}
\hline Ingredients of the polishing liquid & $\begin{array}{c}\text { Weight } \\
\text { ratio(g) }\end{array}$ \\
\hline Magnetic fluid (MSGS60) & 19.6 \\
\hline Carbonyl Fe fine particles (HQ, 1 $\square \mathrm{m}$ ) & 15.2 \\
\hline Polishing particles (alumina 3 $\square \mathrm{m}$ ) & 10 \\
\hline$\alpha$-cellurose & 3.2 \\
\hline Kerosene & 2 \\
\hline
\end{tabular}

TABLE. 2 POLISHING LIQUID 2 (PL2)

\begin{tabular}{|c|c|}
\hline Ingredients of the polishing liquid & $\begin{array}{c}\text { Weight ratio } \\
(\mathrm{g})\end{array}$ \\
\hline Magnetic fluid (MSGS60) & 19.6 \\
\hline Carbonyl Fe fine particles (HQ, $1 \square \mathrm{m})$ & 15.2 \\
\hline Polishing particles (alumina $0.06 \square \mathrm{m})$ & 2.5 \\
\hline a-cellurose & 3.2 \\
\hline Kerosene & 2 \\
\hline
\end{tabular}

TABLE. 3 EXPERIMENTAL CONDITION 1

\begin{tabular}{|c|c|}
\hline $\begin{array}{c}\text { Ingredients of the polishing liquid } \\
\text { Clearance (gap) between the polished body } \\
\text { surface and the polishing tool }\end{array}$ & Same as PL1 \\
\hline Rotary speed of the polishing tool & $515(\mathrm{rpm})$ \\
\hline Polishing time & $60(\mathrm{~min})$ \\
\hline Permanent magnet used & Neodymium magnet \\
\hline Polished body material & $\begin{array}{c}\text { Aluminum (thickness } \\
1 \mathrm{~mm})\end{array}$ \\
\hline Polished body motion & Standstill \\
\hline
\end{tabular}

TABLE. 4 EXPERIMENT CONDITION 2

\begin{tabular}{|c|c|}
\hline Ingredients of the polishing liquid & Same as PL1 \\
\hline $\begin{array}{c}\text { Clearance (gap) between the polished } \\
\text { body's surface and the polishing tool }\end{array}$ & $1,2,3,4,5,6,7,8(\mathrm{~mm})$ \\
\hline Rotary speed of the polishing tool & $515(\mathrm{rpm})$ \\
\hline Polishing time & 60 (minutes) \\
\hline Permanent magnet used & Neodymium magnet \\
\hline Polished body material & $\begin{array}{c}\text { Aluminum (thickness } \\
1 \mathrm{~mm})\end{array}$ \\
\hline Polished body motion & Parallel motion \\
\hline
\end{tabular}




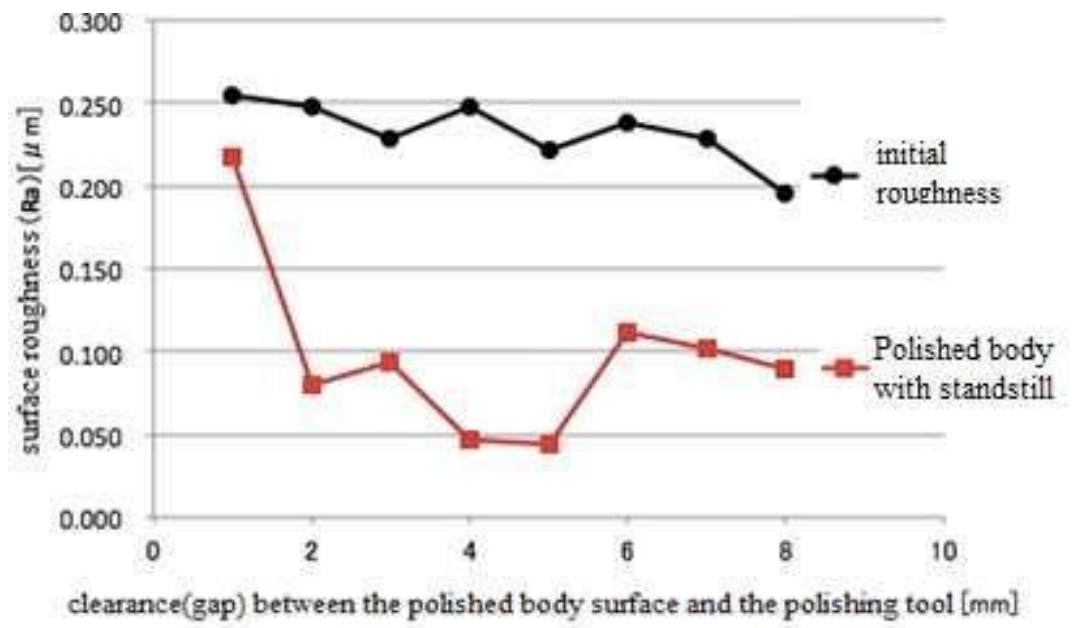

Fig. 3 Results of Experiment 1 (polished material was an aluminium plate)

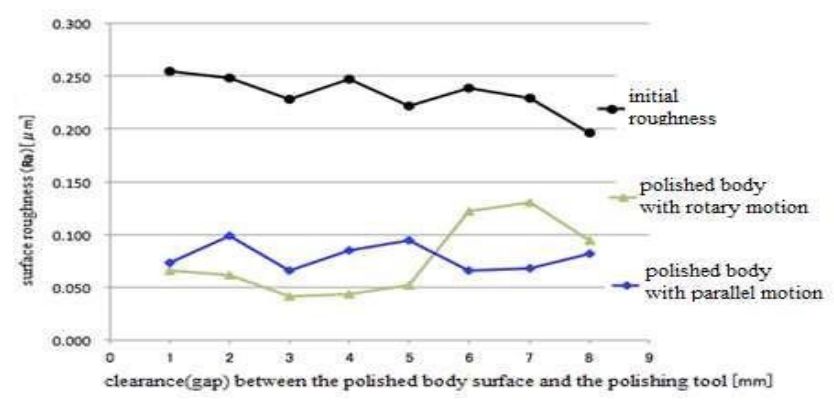

Fig. 4 Results of Experiment 2 (polished material was an aluminium plate)

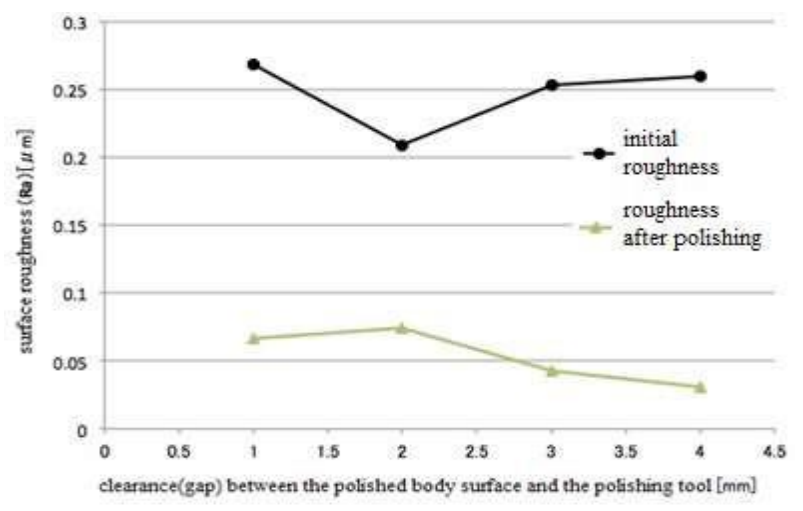

Fig. 5 Results of Experiment 3 (polished material was an aluminium plate)

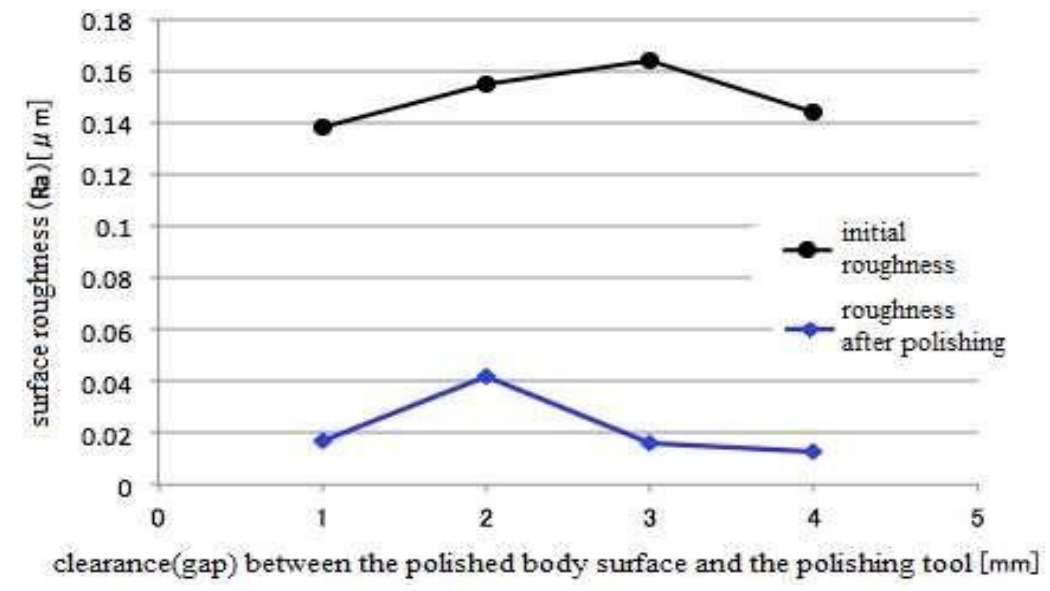

Fig. 6 Results of Experiment 4 (polished material was an acrylic resin plate) 


\section{TABLE.5 EXPERIMENT CONDITION 3}

\begin{tabular}{|c|c|}
\hline Ingredient of the polishing liquid & PL1 and PL2 \\
\hline $\begin{array}{c}\text { Clearance(gap) between the polished body's } \\
\text { surface and the polishing tool }\end{array}$ & $1,2,3,4(\mathrm{~mm})$ \\
\hline Rotary speed of the polishing tool & $515(\mathrm{rpm})$ \\
\hline Polishing time & $\begin{array}{c}30(\mathrm{~min}) \text { with PL1 and } \\
30(\mathrm{~min}) \text { with PL2 }\end{array}$ \\
\hline Permanent magnet used & Neodymium magnet \\
\hline Polished body material & Aluminum(thickness $1 \mathrm{~mm})$ \\
\hline Polished body motion & Parallel motion \\
\hline
\end{tabular}

TABLE. 6 EXPERIMENT CONDITION 4

\begin{tabular}{|c|c|}
\hline Ingredient of the polishing liquid & PL2 \\
\hline $\begin{array}{c}\text { Clearance(gap) between the polished } \\
\text { body's surface and the polishing tool }\end{array}$ & $1,2,3,4(\mathrm{~mm})$ \\
\hline Rotary speed of the polishing tool & $515(\mathrm{rpm})$ \\
\hline Polishing time & $60(\mathrm{~min})$ \\
\hline Permanent magnet used & Neodymium magnet \\
\hline Polished body's material & $\begin{array}{c}\text { Acrylic resin(thickness } \\
5 \mathrm{~mm})\end{array}$ \\
\hline Polished body motion & Parallel motion \\
\hline
\end{tabular}

\section{Conclusions}

We varied abrasive materials and experimental conditions in the experiments. The result demonstrated that the most suitable clearance (gap) between the polishing tool head and polished body surface was about $4 \mathrm{~mm}$. When the clearance (gap) was smaller than $4 \mathrm{~mm}$, the magnetic density was higher, and magnetic clusters become overcrowded. Therefore, the polishing process became similar to a cutting process with the body of the polished body cut and reduced surface roughness. Conversely, when the clearance (gap) was larger than $4 \mathrm{~mm}$, the magnetic density was lower, and there were too few magnetic clusters. As a result, polishing power became insufficient, and the abrasion effect too small. Thus, there was a most suitable clearance (gap), and it was about $4 \mathrm{~mm}$.

\section{References}

[1].Shimada K, Fujita T, Oka H, Akagami Y and Kamiyama S 2001 Hydrodynamic and magnetized characteristics of MCF (magnetic compound fluid) Transactions of the Japan Society of Mechanical Engineers 664-67(B) 122-128

[2].Shimada K, Akagami Y, Fujita T, Miyazaki T, Kamiyama S and Shibayama A 2002

[3].Characteristics of MCF (Magnetic Compound Fluid) in a rotating rheometer Journal of Magnetism Magnetic and Materials 252 235-237

[4].Shimada K, Fujita T, Kamiyama S and Akagami Y Experimental investigation of effects by various factors on shear flow characteristics of magnetic compound fluid (MCF) and its application 2002 Journal of the Japan Society of Applied Electromagnetics and Mechanics 10-1 67-72

[5].Fujita T and Shimada K 2003 Characteristics and application of magnetorheological fluid Recent Research Development Magnetism and Magnetic Materials 1 463-479

[6].Shimada K, Akagami Y, Kamiyama S, Fujita T, Miyazaki T and Shibayama A 2002 New microscopic polishing with magnetic compound fluid (MCF) Journal of Intelligent of Material Systems Structure, 13-7 405-408

[7].Shimada K, Wu Y, Wong Y C, Fujita T, Miyazaki T and Shibayama A 2002 Experimental investigation of the effect of the MPL (magnetic polishing liquid) on surface finishing Proceedings of SPIE 4936 312-320

[8].Shimada K, Wu Y, Matsuo Y and Yamamoto K 2005 Float polishing technique using new tool consisting of micro magnetic clusters Journal of Material Processing Technology 162-163 690-695 [8] Wong Y C, Wu Y, Shimada K and Kato M 2002 The effects of polishing with magnetic compound fluid Proceedings of 5th International Conference on Behavior of Materials in Machining 293-296

[9].Komanduri R, Umehara N and Raghunandan M 1996 On the possibility of chemo-mechanical action in magnetic float polishing of silicon nitride Transactions of ASME, Journal of Tribology 1184 721-727

[10]. Childs T H C and Moss D J 2000 Grinding ratio and cost issues in magnetic and non-magnetic fluid grinding Annals of the CIRP 49-1 261-264

[11]. Raghunandan M, Umehara N, Noori-Khajavi A, Komanduri R 1997 Magnetic float polishing of ceramics Transactions of ASME, Journal of Manufacture Science Engineering 119-4 520-528 [12] Jiang M and Komanduri R 1997 Application Taguchi method for optimization of finishing conditions in magnetic float polishing (MFP) Wear 213 59-71 
[12]. Arrasmith S R, Kozhinova I A, Gregg L L, Shorey A B, Romanofsky H J, Jacobs S D, Golini D, Kordonski W I, Hogan S and Dumas P 1999 Details of the polishing spot in magnetorheological finishing (MRF) Proceedings of SPIE 3782 92-100

[13]. Komandiru R and Golini D 1999 Fundamentals of magneto-rheological fluid utilization in high precision finishing Journal of Intelligent Material Science Structure 10 683-689

[14]. Shorey A B, Jacobs S D, Kordonski W I and Gans R F 2001 Experiments and observations regarding the mechanisms of glass removal in magnetorheological finishing Appied. Optics 40-1 2033

[15]. Shimada K, Miyazaki T, Shibayama A and Fujita T 2003 Extraction of magnetic clusters self-assembled by a magnetic field Smart Materials and Structures 12-2 297-303 